\title{
A Novel Framework of Integrating UV and NIR Atmospheric Correction Algorithms for Coastal Ocean Color Remote Sensing
}

\author{
Feng Qiao ${ }^{1,2}{ }^{\oplus}$, Jianyu Chen ${ }^{1,2,3,4, *}$, Zhihua Mao ${ }^{1,2,3}{ }^{-}$, Bing Han ${ }^{5}$, Qingjun Song ${ }^{6,7}$, Yuying $\mathrm{Xu}^{2,4}$ \\ and Qiankun $\mathrm{Zhu}{ }^{2,3}$
}

check for

updates

Citation: Qiao, F.; Chen, J.; Mao, Z.; Han, B.; Song, Q.; Xu, Y.; Zhu, Q. A Novel Framework of Integrating UV and NIR Atmospheric Correction Algorithms for Coastal Ocean Color Remote Sensing. Remote Sens. 2021, 13, 4206. https://doi.org/10.3390/ rs13214206

Academic Editors: Jungho Im and Yonghoon Kim

Received: 16 August 2021

Accepted: 2 October 2021

Published: 20 October 2021

Publisher's Note: MDPI stays neutral with regard to jurisdictional claims in published maps and institutional affiliations.

Copyright: (c) 2021 by the authors. Licensee MDPI, Basel, Switzerland. This article is an open access article distributed under the terms and conditions of the Creative Commons Attribution (CC BY) license (https:// creativecommons.org/licenses/by/ $4.0 /)$.
1 School of Oceanography, Shanghai JiaoTong University, Shanghai 200030, China; qiaofeng@sjtu.edu.cn (F.Q.); mao@sio.org.cn (Z.M.)

2 State Key Laboratory of Satellite Ocean Environment Dynamics, Second Institute of Oceanography, Ministry of Natural Resources, Hangzhou 310012, China; yyxu@zju.edu.cn (Y.X.); zhuqiankun@sio.org.cn (Q.Z.)

3 Southern Marine Science and Engineering Guangdong Laboratory (Guangzhou), Guangzhou 511458, China

4 Ocean College, Zhejiang University, Zhoushan 316021, China

5 National Ocean Technology Center, State Oceanic Administration, Tianjin 300112, China; hotrice@sina.com

6 National Satellite Ocean Application Service, Ministry of Natural Resources, Beijing 100081, China; songqingjun@mail.nsoas.org.cn

7 Key Laboratory of Space Ocean Remote Sensing and Application, Ministry of Natural Resources, Beijing 100081, China

* Correspondence: chenjianyu@sio.org.cn

\begin{abstract}
Atmospheric correction is a fundamental process of ocean color remote sensing to remove the atmospheric effect from the top-of-atmosphere. Generally, Near Infrared (NIR) based algorithms perform well for clear waters, while Ultraviolet (UV) based algorithms can obtain good results for turbid waters. However, the latter tends to produce noisy patterns for clear waters. An ideal and practical solution to deal with such a dilemma is to apply NIR- and UV-based algorithms for clear and turbid waters, respectively. We propose a novel atmospheric correction method that integrates the advantages of UV- and NIR-based atmospheric correction (AC) algorithms for coastal ocean color remote sensing. The new approach is called UV-NIR combined AC algorithm. The performance of the new algorithm is evaluated based on match-ups between GOCI images and the AERONET-OC dataset. The results show that the values of retrieved Rrs (Remote Sensing Reflectance) at visible bands agreed well with the in-situ observations. Compared with the SeaDAS (SeaWiFS Data Analysis System) standard NIR algorithm, the new AC algorithm can achieve better precision and provide more available data.
\end{abstract}

Keywords: integrated algorithm; ocean color; atmospheric correction; UV-NIR

\section{Introduction}

The Geostationary Ocean Color Imager (GOCI), the world's first geostationary ocean color spaceborne instrument, is onboard the Communication, Ocean, and Meteorological Satellite (COMS), which was launched in 2010 [1]. The GOCI offers moderate spatial resolution data $(500 \mathrm{~m} \times 500 \mathrm{~m}$ ) for six visible bands and two infrared bands (centered around 412, 443, 490, 555, 660, 680, 745, and $865 \mathrm{~nm}$ ) every hour during the daytime from 00:15 to 07:15 UTC. Its high-frequency sea-surface observation capability provides effective monitoring data for dynamic marine environment research. During the past 10 years, a large number of studies utilized the GOCI data for monitoring short-term coastal ocean phenomena, including suspended sediment dynamics [2-5], red tides [6,7], and tidal variability [8-10].

The effective use of the GOCI data depends on the atmospheric correction (AC) algorithm and ocean color information acquisition capabilities of the GOCI data [11]. The process of removing the influence of the atmosphere from the radiation signal received by 
the sensor is called AC [12]. In the AC process, the dominant contribution of the Rayleigh scattering can be accurately computed using a radiative transfer model with the inputs of solar-sensor geometries, atmospheric pressure, and surface wind speed, without using the remotely sensed data [13-15]. The difficulty of the AC is how to determine the type of aerosols and eliminate the scattering and absorption contribution of aerosols because of their unique optics and their temporal and spatial changes [16-18].

The widely used AC algorithm developed by Gordon and Wang [12] assumes that the reflectance from water is zero in the NIR (Near Infrared) band when estimating the aerosol scattering ratio $(\varepsilon)[12,19]$. The algorithm selects the closest aerosol model from candidate aerosol models, based on $\varepsilon$, and then extrapolates aerosol reflectance from NIR band to visible band $[20,21]$. This algorithm has given good results in the open ocean. However, in turbid coastal water, the reflectance from water in the NIR band is no longer zero, and the hypothesis of NIR "dark pixel" is no longer applicable. To overcome this problem, various AC algorithms use an iterative optimization scheme to separate water and aerosol reflectance in the NIR [22-25]. However, these iterative schemes result in biased estimations in ocean color products for the complex turbid waters [26,27]. To address this issue, Wang and Shi [28] proposed a NIR-SWIR (NIR-Short Wave Infrared) combined algorithm for AC of MODIS images. This method takes advantage of much stronger water absorption for the SWIR wavelengths and uses a turbidity index to apply a NIR-based algorithm for clear waters and a SWIR-based algorithm for turbid waters [29]. However, most current ocean color remote sensors, such as the Sea-viewing Wide Field-of-View Sensor (SeaWiFS), Medium Resolution Imaging Spectrometer (MERIS), and GOCI, do not include SWIR bands, which limits the application of this method. He et al. [30] proposed an AC algorithm based on the assumption of UV (Ultraviolet) "dark pixel" (UV-AC). The UV-AC algorithm produces good corrections for turbid waters.

The AC algorithms have advantages and disadvantages. There are four commonly used AC algorithms for the GOCI data process, including the UV-AC algorithm [30], KOSC standard AC (KOSC-STD) algorithm [31], NASA standard (NASA-STD) AC algorithm [23], and MUMM algorithm [32]. None of them can handle the AC for both clear and turbid waters perfectly. An ideal and practical solution to such a dilemma is to apply NIR- and UV-based algorithms for clear and turbid waters, respectively. The UV-AC method can be used to replace the SWIR method, the NIR algorithm for clean pixels, and the UV-AC method for turbid pixels.

In this study, we analyze the currently widely used GOCI image AC methods and use simulation datasets to evaluate the accuracy of three NIR-AC and one UV-AC algorithm. A novel AC method, called as UV-NIR combined AC algorithm, is proposed, which integrates the advantages of UV and NIR AC algorithms for GOCI coastal ocean color remote sensing. The new approach divides the applicable areas of the UV and NIR AC algorithms. After analyzing the application area of the UV and NIR AC algorithms and the characteristic cross-section remote sensing reflectance spectrum, a joint UV and NIR AC algorithm is constructed. Moreover, it is performed on the GOCI images of the Bohai Sea and the East China Sea, which contain both clear and turbid waters.

\section{Materials and Methods}

We use AC for retrieving water reflectance at the sea surface $\left(\rho_{w n}\right)$ by removing atmospheric reflectance. Ignoring the sunglint, whitecaps, and effects of bidirectional reflectance, the reflectance at the top of the atmosphere (TOA) $\left(\rho_{T O A}\right)$ at wavelength $\lambda$ can be described by [12]:

$$
\begin{gathered}
\rho_{T O A}(\lambda)=\frac{\pi L_{T O A}(\lambda)}{F_{0}(\lambda) \cos \theta} \\
\rho_{T O A}(\lambda)=\rho_{r}(\lambda)+\rho_{a}(\lambda)+t_{d}^{v}(\lambda) t_{d}^{s}(\lambda) \rho_{w n}(\lambda)
\end{gathered}
$$

where $L_{T O A}$ is the TOA radiance, $F_{0}$ is the extraterrestrial solar irradiance, and $\theta$ is the solar zenith angle. $\rho_{r}(\lambda)$ is Rayleigh reflectance in the absence of aerosols, and $\rho_{a}(\lambda)$ is aerosol scattering reflectance. $t_{d}^{v}$ and $t_{d}^{s}$ are the upward and downward diffuse transmittances, respectively. 
$\rho_{r}(\lambda)$ can be predicted given solar-sensor angular geometries and the air pressure at the surface through radiative transfer simulation with less than $\sim 1 \%$ error $[13,14,33]$. The Rayleigh corrected reflectance $\left(\rho_{r c}(\lambda)\right)$ can be derived as follows:

$$
\rho_{r c}(\lambda)=\rho_{T O A}(\lambda)-\rho_{r}(\lambda)=\rho_{a}(\lambda)+t_{d}^{v}(\lambda) t_{d}^{s}(\lambda) \rho_{w n}(\lambda)
$$

To solve $\rho_{w n}$ using Equation (3), the aerosol reflectance in the visible wavelengths is estimated first from the observed aerosol reflectance at the two NIR wavelengths or UV wavelengths based on the "dark pixel" assumption.

\subsection{NASA-STD AC Algorithm}

The NASA-STD AC algorithm uses a bio-optical model iterative process based on the Gordon and Wang method [12] for turbid water atmospheric correction. This method uses 80 types of aerosols built from the AERONET observations and vector radiative transfer code for the ocean-atmosphere system [21] and is currently the default AC algorithm of the SeaDAS software. It first uses the NIR band "dark pixel" method to obtain the water-leaving reflectance of the visible bands at 443 and $555 \mathrm{~nm}$ and then inputs the water-leaving reflectance at 443- and 555-nm bands into the bio-optical model (OBPG OC3 algorithm [34]) to determine chlorophyll concentration. Next, the backscattering coefficient at the 660-nm band is calculated according to the chlorophyll-a concentration, and the backscattering coefficient in the NIR band $b_{b p}(N I R)$ is calculated according to the relationship between $660 \mathrm{~nm}$ and the water backscattering coefficient in the NIR band [35]. The NIR water-leaving reflectance can then be calculated.

\subsection{UV AC Algorithm}

He et al. [30] studied a large number of in-situ water-leaving spectra of turbid estuary water bodies such as the Yangtze River, Mississippi River, and Orinoco River; they found that due to the high suspended solids concentration in the water body, the NIR radiation from water increased significantly. Meanwhile, due to the strong absorption of detritus, water-leaving radiance is significantly low in UV, which can be neglected [30]. Therefore, AC can be carried out through the UV band, that is, the UV algorithm. For the GOCI, He et al. [2] used $412 \mathrm{~nm}$ to estimate aerosol scattering. It first assumes the reflectance from water at $412 \mathrm{~nm}$ is 0 , the aerosol scattering reflectance at $412 \mathrm{~nm}$ is equal to Rayleigh scattering correction reflectance $\left(\rho_{r c}\right)$, and then estimates the aerosol scattering reflectance at $865 \mathrm{~nm}$ using the medium precision extrapolation model [12]. Next, it assumes that the $865 \mathrm{~nm}$ aerosol scattering reflectance is approximately the contribution of aerosol scattering in all bands $\left(\rho_{a}(\lambda)\right)$. The normalized water-leaving reflectance and remote sensing reflectance of water can be obtained by removing $\rho_{a}(\lambda)$.

\subsection{UV-NIR Jointed AC Algorithm}

Through the analysis of the NASA-STD AC algorithm and specific implementation process of the UV AC (412 nm) algorithm, the starting point of the UV AC (412 nm) and NASA-STD AC is to assume that the water leaving reflectance of 412-nm or 865-nm band is zero; and the reflectance after Rayleigh correction is regarded as the contribution of aerosol scattering, which is then extrapolated to other bands' aerosol scattering rates to complete AC. Therefore, the pixel can be divided into pixels processed by the UV or NIR AC algorithm according to the reflectance after Rayleigh correction at the 412-nm waveband and the 865-nm waveband. When $\rho_{r c}(412)<\rho_{r c}(865)$, the UV AC (412 nm) algorithm should be used, otherwise, use the NIR AC algorithm. The flowchart of integrating UV and NIR AC algorithms is shown in Figure 1. 


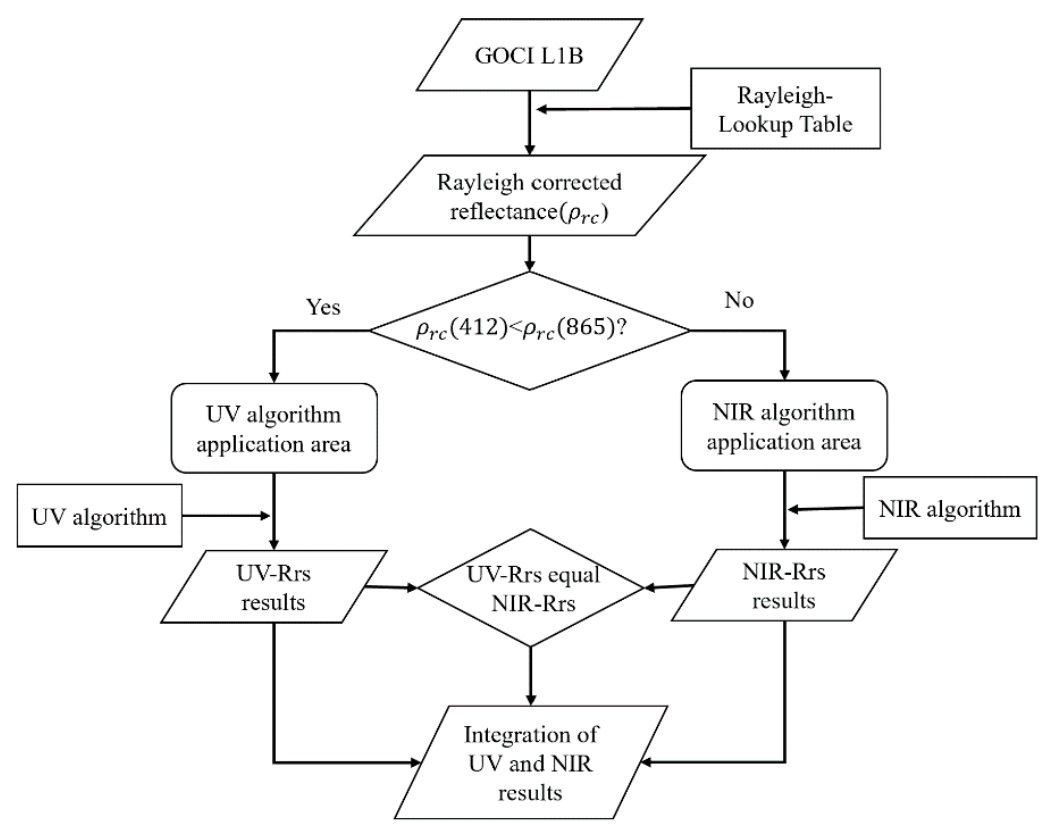

Figure 1. The flowchart of integrating UV and NIR AC algorithms.

(a) We use the GOCI Rayleigh scattering lookup table to perform Rayleigh scattering correction on the apparent reflectance of the TOA and obtain the Rayleigh scattering corrected reflectance for the 412-, 443-, 490-, 555-, 660-, 680-, 745-, and 865-nm bands.

(b) According to the reflectance of 412- and 865-nm Rayleigh scattering correction, the applicable area of the AC algorithm is divided. The pixels of $\rho_{r c}(412)<\rho_{r c}(865)$ are the area of using the UV AC $(412 \mathrm{~nm})$ algorithm; the pixels of $\rho_{r c}(412)>\rho_{r c}(865)$ are the area of using the NIR AC algorithm.

(c) The UV and NASA-STD AC algorithms are applied to the applicable areas of the UV and NIR AC algorithms obtained in step 2 to obtain the remote sensing reflectance $\left(R_{r s}\right)$.

(d) We utilize the UV AC (412 nm) algorithm for the pixels that have failed to use the NASA-STD AC algorithm and identify the pixels with the same remote sensing reflectance of the UV algorithm and NIR remote sensing reflectance; we use the UV $\mathrm{AC}(412 \mathrm{~nm})$ remote sensing reflectance results on the shore side, and NASA-STD AC remote sensing reflectance results on the far shore side are accepted.

(e) Finally, we integrate the remote sensing reflectance results of the UV algorithm application area, the NIR algorithm application area, and the transition area to obtain the whole AC result.

\subsection{Simulated, GOCI and In-Suit Data}

\subsubsection{Simulated Top of Atmospheric (TOA) Reflectance}

The NASA-STD, KOSC, and MUMM AC algorithms use NIR bands to estimate aerosol reflectance. We use simulated datasets to evaluate the accuracy of these three NIR AC algorithms and select the most accurate AC algorithm to combine with the UV AC (412 nm) algorithm. To generate a set of aerosol data containing broad aerosol properties, the Second Simulation of a Satellite Signal in the Solar Spectrum Vector Version 1.1 (6SV1.1) [36-38] was used to simulate aerosol reflectance. The input parameters are shown in Table 1 . The solar and satellite geometry, zenith angle, and azimuth angle were extracted from the GOCI L2P file. 
Table 1. Parameters and values used in generating aerosol reflectance using 6SV1.1.

\begin{tabular}{ll}
\hline Parameters & Values \\
\hline Atmospheric Profile & Midlatitude Summer \\
Aerosol Model & Continental, Marine \\
Aerosol Optical Thickness (at $550 \mathrm{~nm})$ & $0.1,0.2$ \\
Target Altitude & Sea Level \\
Sensor Altitude & Sensor Satellite Level \\
\hline
\end{tabular}

The simulated hyperspectral ocean color dataset provided by Nechad et al. [39] was used in this study because it consists of 5000 samples with a broad range of apparent optical properties (AOP) and inherent optical properties (IOP) ranging from 350 to $900 \mathrm{~nm}$. The ranges of chlorophyll-a suspended sediment concentration and absorption coefficients $(443 \mathrm{~nm})$ of colored dissolved organic matter are $0 \sim 214.41\left(\mathrm{mg} / \mathrm{m}^{3}\right), 0 \sim 492.77\left(\mathrm{~g} / \mathrm{m}^{3}\right)$, and $0 \sim 14.83(1 / \mathrm{m})$, respectively. The water-leaving reflectance spectra with zero solar and sensor zenith angles were used since they are equivalent to normalized water-leaving reflectance, and we do not need to consider the bidirectional reflectance distribution function effect. One simulated $\rho_{w n}$ was selected for one simulated aerosol reflectance. The simulated Rayleigh-corrected reflectance was obtained by combining simulated aerosol and $\rho_{w n}$ using $\rho_{r c}(\lambda)=\rho_{a}(\lambda)+t_{d}^{v}(\lambda) t_{d}^{s}(\lambda) \rho_{w n}(\lambda)$. A total of 20,000 Rayleigh-corrected reflectance spectra were obtained.

\subsubsection{GOCI and In-Suit Data}

The spectra of in-situ Rrs were derived from Aerosol Robotic NETWORK-Ocean Color (AERONET-OC https:/ / aeronet.gsfc.nasa.gov/new_web/ocean_color.html accessed date 4 October 2021) observations [40] and two Chinese ocean observation platforms (Station Muping and Station Dongou) locations are illustrated in Figure 2. The level 1B GOCI images collocated with in-situ samples were downloaded from the Korea Ocean Satellite Center (http: / / kosc.kiost.ac.kr/ accessed date 4 October 2021). Match-ups between the in-situ and GOCI-retrieved Rrs were selected based on locations and overpass times. The slight difference in the wavelength between the in-situ and satellite-retrieved values was ignored. First, $3 \times 3$ pixel boxes were extracted from the GOCI image centered on the measurement sites. Second, a coefficient of variation $(\mathrm{CV}$, which is the standard deviation divided by mean values) was calculated for each band to account for spatial homogeneity of the pixels within each $3 \times 3$ box. Match-ups with CV values $>0.2$ in $3 \times 3$ pixel boxes were excluded. Finally, the mean value of the remaining pixels was calculated. The in-suit data and the number of observations for each site are given in Table 2.

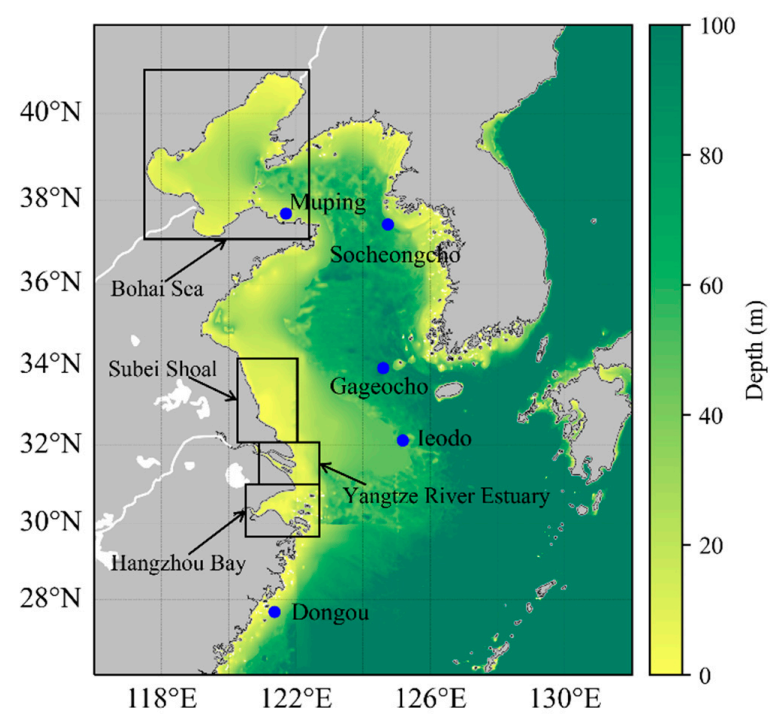

Figure 2. Locations of five sampling stations and study area. 
Table 2. In-suit data location, description, and number of match-ups.

\begin{tabular}{cccccc}
\hline Stations & $\begin{array}{c}\text { Lat } \\
\left({ }^{\circ} \mathbf{N}\right)\end{array}$ & $\begin{array}{c}\text { Lon } \\
\left({ }^{\circ} \mathbf{E}\right)\end{array}$ & $\begin{array}{c}\text { Time- } \\
\text { Window }\end{array}$ & Data Period & $\begin{array}{c}\text { Number of } \\
\text { Match-Ups }\end{array}$ \\
\hline Gageocho & 33.94 & 125.59 & $\pm 0.5 \mathrm{~h}$ & October 2011-May 2012 & 10 \\
Ieodo & 32.12 & 125.18 & $\pm 0.5 \mathrm{~h}$ & December 2013-February 2018 & 20 \\
Socheongcho & 37.42 & 124.73 & $\pm 0.5 \mathrm{~h}$ & May 2016-May 2019 & 8 \\
Dongou & 27.68 & 121.70 & $\pm 0.5 \mathrm{~h}$ & January 2020-October 2020 & 25 \\
Muping & 37.68 & 121.35 & $\pm 0.5 \mathrm{~h}$ & September 2020-September 2020 & 6 \\
\hline
\end{tabular}

\subsection{Performance Assessment}

For quantitative performance assessment of the AC algorithms, different statistical matrices were used, namely, mean absolute percentage deviation (APD), root mean square error (RMSE), and the bias, as well as correlation coefficient $\left(R^{2}\right)$.

$$
\begin{gathered}
A P D=\frac{1}{N} \sum_{i=1}^{N}\left|\frac{Y_{i}-X_{i}}{X_{i}}\right| \times 100 \% \\
\text { RMSE }=\sqrt{\frac{1}{N} \sum_{i=1}^{N}\left(Y_{i}-X_{i}\right)^{2}} \\
\text { Bias }=\frac{1}{N} \sum_{i=1}^{N}\left(Y_{i}-X_{i}\right)
\end{gathered}
$$

where $X_{i}, Y_{i}$, and $N$ are the in-situ value, retrieved value, and sample number, respectively.

\section{Results}

\subsection{Evaluation of NIR Algorithms Using Simulated Data}

Figures 3-5 and Table 3 compare AC results obtained by the KOSC algorithm, MUMM, and NASA-STD algorithm for the bands of 412, 443, 490, 555, 660, and $680 \mathrm{~nm}$. The color in the figures represents the probability density of the scattered points; the redder the color, the greater the probability density. The solid black line is the 1:1 line, and the green dashed line is the fitting line of each band. It is clear that Rrs retrieval accuracy depends on the AC algorithm. The KOSC algorithm overestimates Rrs in all bands. The MUMM and NASA-STD algorithms overestimate Rrs in the 443 and 490 bands. Table 3 shows that the inversion values of the three NIR AC algorithms have a high correlation with the simulated remote sensing reflectance. In the 490-, 555-, 660-, and 680-nm bands, $R^{2}>0.94$; in the 443-nm band, the KOSC and NASA-STD algorithms have $R^{2}>0.8$, and the MUMM algorithm has $R^{2}=0.74$. The correlation in the 412-nm band is relatively low, and the $R^{2}$ of the KOSC, MUMM, and NASA-STD algorithms are 0.61, 0.54, and 0.61, respectively. The results of the three algorithms all show that at 490 and $555 \mathrm{~nm}$, the remote sensing reflectance obtained is in good agreement with the simulated reflectance, and the APDs of the three algorithms in these two bands are between $12.14 \%$ and $20.94 \%$ and between $5.39 \%$ and $13.52 \%$, respectively. 

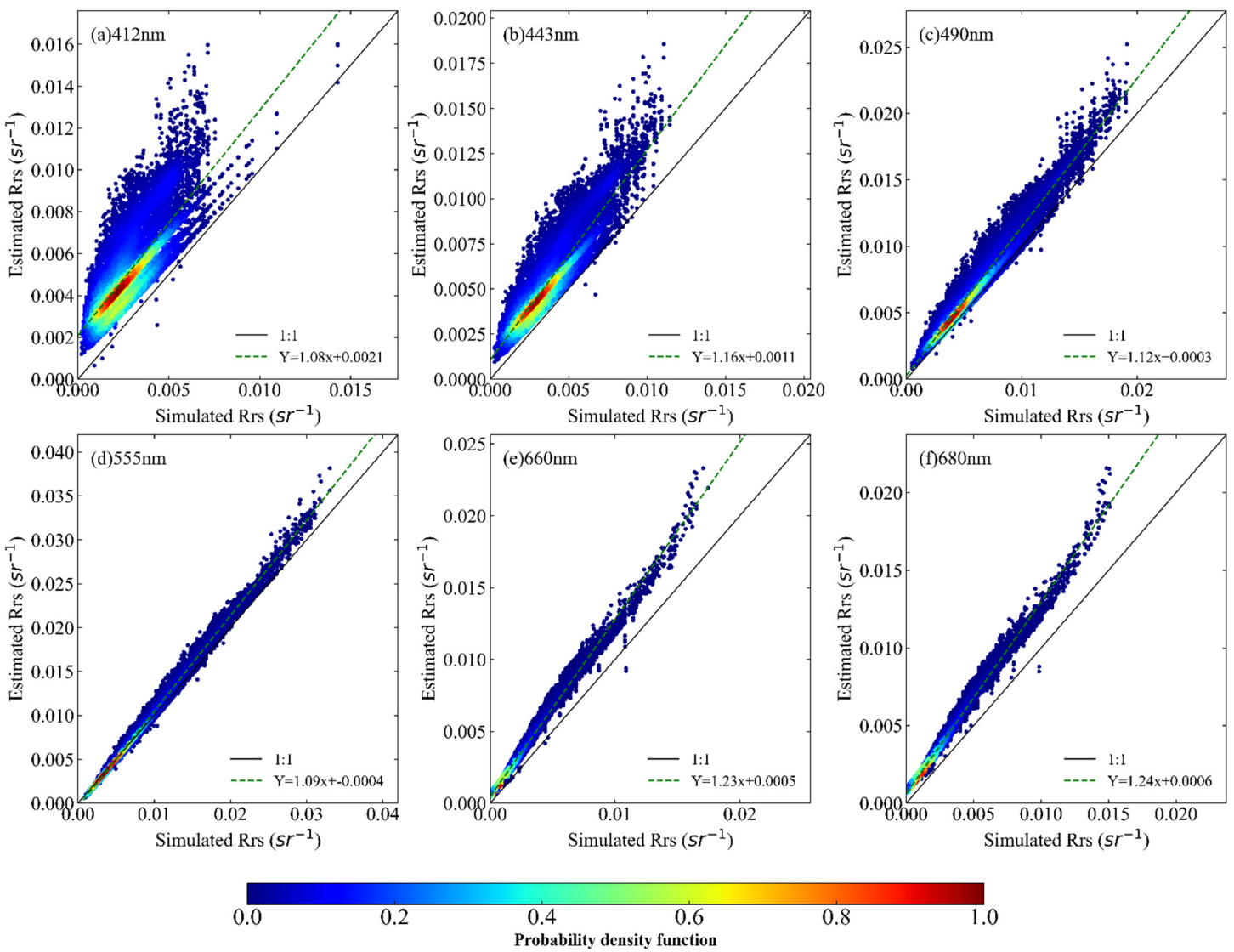

Figure 3. Scatterplots of estimated vs. simulated remote sensing reflectance (Rrs) at 412, 443, 490, 555, and $660 \mathrm{~nm}$, obtained using the KOSC algorithm. The solid is 1:1 line, and the dashed line is the regression line.
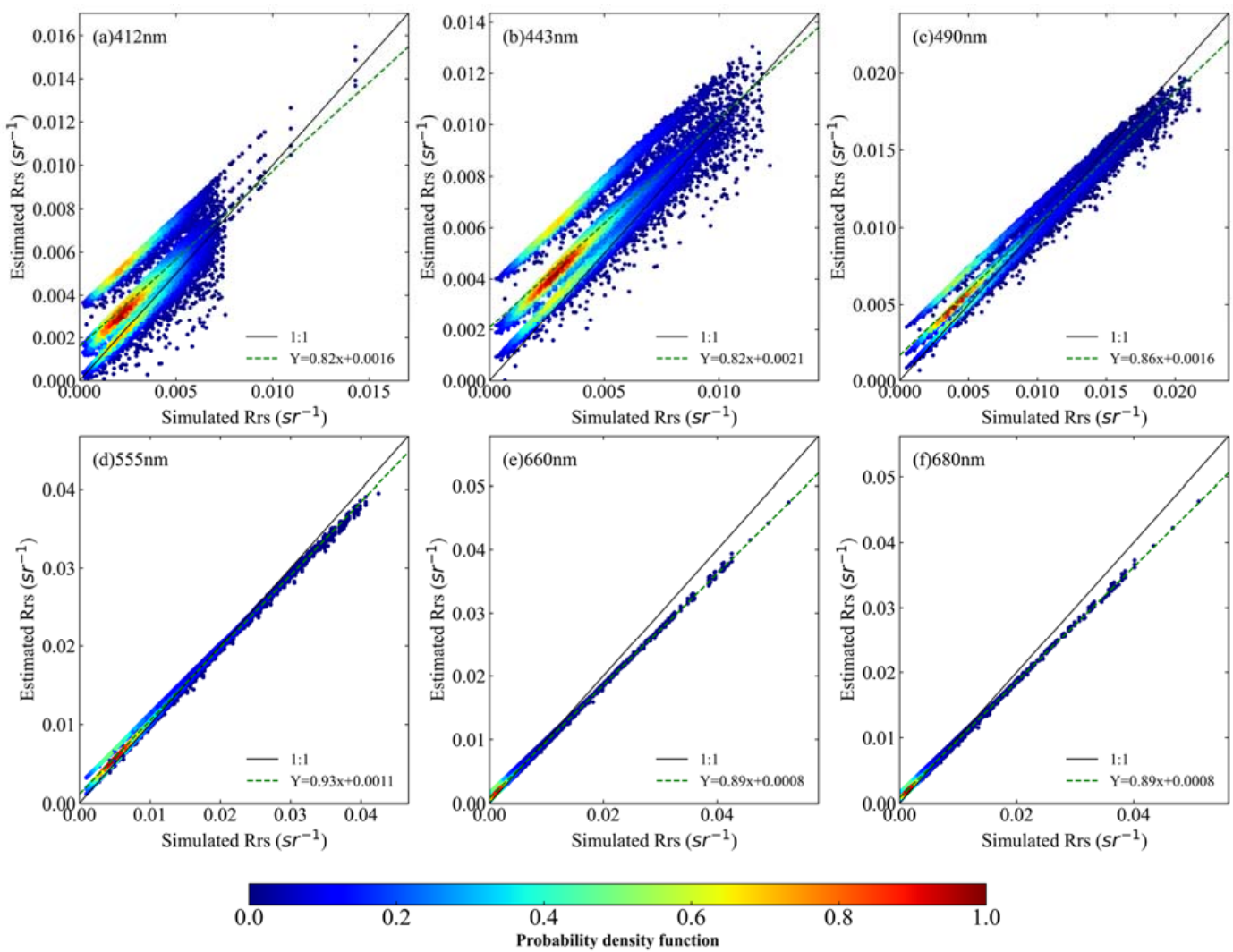

Figure 4. Same as Figure 3, except using the MUMM algorithm. 

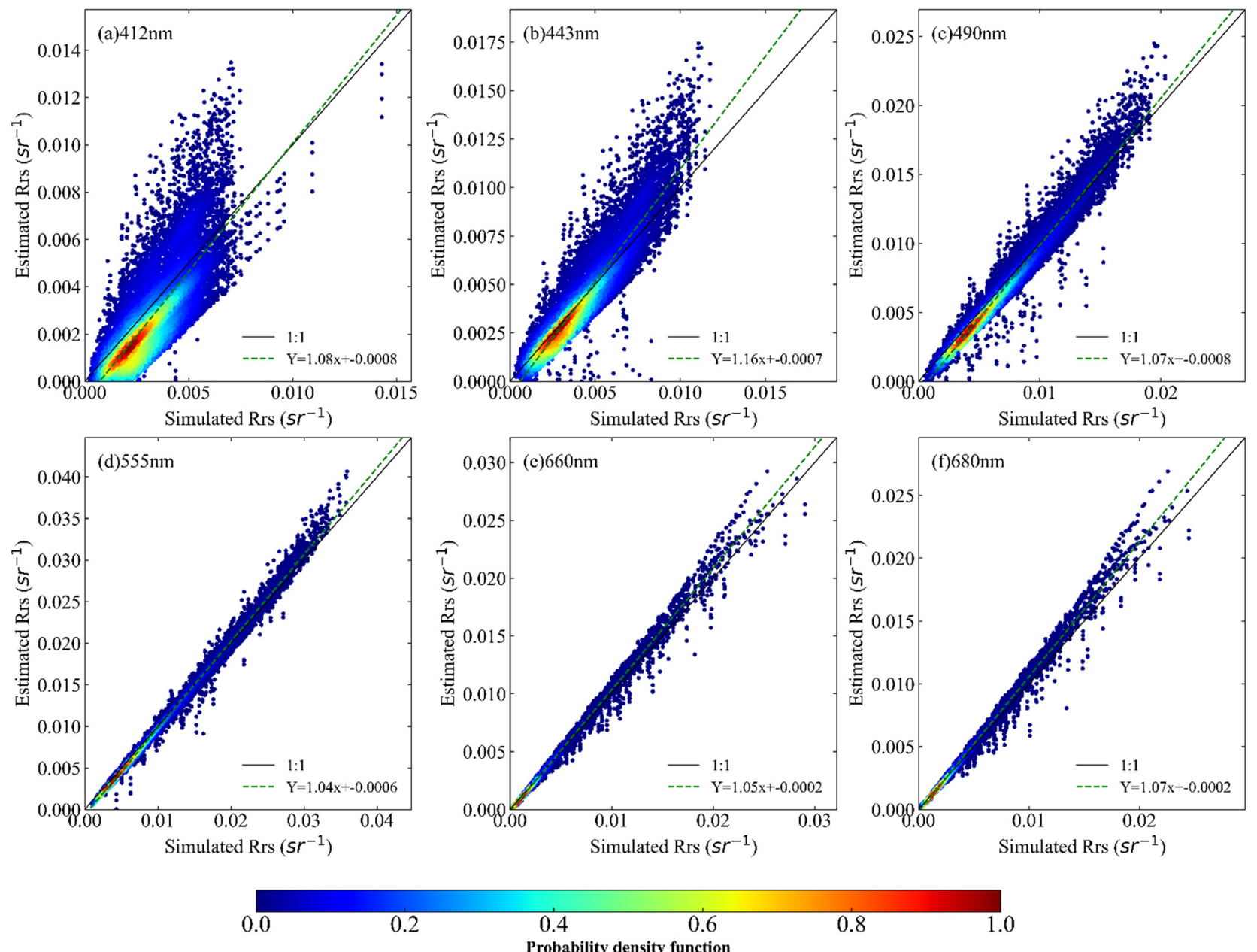

Figure 5. Same as Figure 3, except using the NASA-STD algorithm.

Table 3. Statistical results for the retrieved values of $R_{r s}$ obtained with KOSC, MUMM, and NASASTD algorithms.

\begin{tabular}{ccccccccc}
\hline Algorithm & $\boldsymbol{R}_{\boldsymbol{r s}}(\boldsymbol{\lambda})$ & APD & RMSE & Bias & $\boldsymbol{R}^{2}$ & Slope & Intercept & $\mathbf{N}$ \\
\hline \multirow{6}{*}{ KOSC } & $412 \mathrm{~nm}$ & 109.95 & 0.0026 & 0.0023 & 0.61 & 1.08 & 0.0021 & 16808 \\
& $443 \mathrm{~nm}$ & 55.77 & 0.0020 & 0.0016 & 0.82 & 1.16 & 0.0011 & 16807 \\
& $490 \mathrm{~nm}$ & 18.67 & 0.0012 & 0.0009 & 0.96 & 1.12 & 0.0003 & 16817 \\
& $555 \mathrm{~nm}$ & 5.39 & 0.0007 & 0.0003 & 0.99 & 1.09 & 0.0004 & 16824 \\
& $660 \mathrm{~nm}$ & 68.32 & 0.0011 & 0.0009 & 0.99 & 1.23 & 0.0005 & 16826 \\
& $680 \mathrm{~nm}$ & 72.36 & 0.00132 & 0.0011 & 0.99 & 1.24 & 0.0006 & 16824 \\
\hline \multirow{6}{*}{ MUMM } & $412 \mathrm{~nm}$ & 59.47 & 0.0015 & 0.0010 & 0.54 & 0.82 & 0.0016 & 19778 \\
& $443 \mathrm{~nm}$ & 51.24 & 0.0017 & 0.0013 & 0.74 & 0.82 & 0.0021 & 19783 \\
& $490 \mathrm{~nm}$ & 20.94 & 0.0011 & 0.0006 & 0.94 & 0.86 & 0.0016 & 19783 \\
& $555 \mathrm{~nm}$ & 13.52 & 0.0008 & 0.0004 & 0.99 & 0.93 & 0.0011 & 19783 \\
& $660 \mathrm{~nm}$ & 62.40 & 0.0008 & 0.0003 & 0.99 & 0.89 & 0.0008 & 19783 \\
& $680 \mathrm{~nm}$ & 48.23 & 0.0007 & 0.0004 & 0.99 & 0.89 & 0.0008 & 19783 \\
\hline \multirow{6}{*}{ NASA- } & $412 \mathrm{~nm}$ & 40.16 & 0.0013 & -0.0005 & 0.61 & 1.08 & 0.0008 & 17888 \\
& $443 \mathrm{~nm}$ & 20.27 & 0.0010 & -0.0002 & 0.85 & 1.16 & 0.0007 & 19300 \\
& $550 \mathrm{~nm}$ & 12.14 & 0.0008 & -0.0003 & 0.96 & 1.07 & 0.0008 & 19424 \\
& $660 \mathrm{~nm}$ & 7.27 & 0.0006 & -0.0002 & 1.0 & 1.04 & 0.0006 & 19440 \\
& $680 \mathrm{~nm}$ & 7.17 & 0.0003 & 0.00006 & 0.99 & 1.07 & 0.0002 & 19441 \\
\hline
\end{tabular}


Figure 6 shows the APDs of Rrs retrieved using the KOSC, MUMM, and NASA-STD algorithms. The three algorithms all show the same pattern, and the APD decreases as the simulated Rrs increases. However, the APD of the NASA-STD algorithm is always the smallest. So, we choose the combination of NASA-STD and UV algorithms.
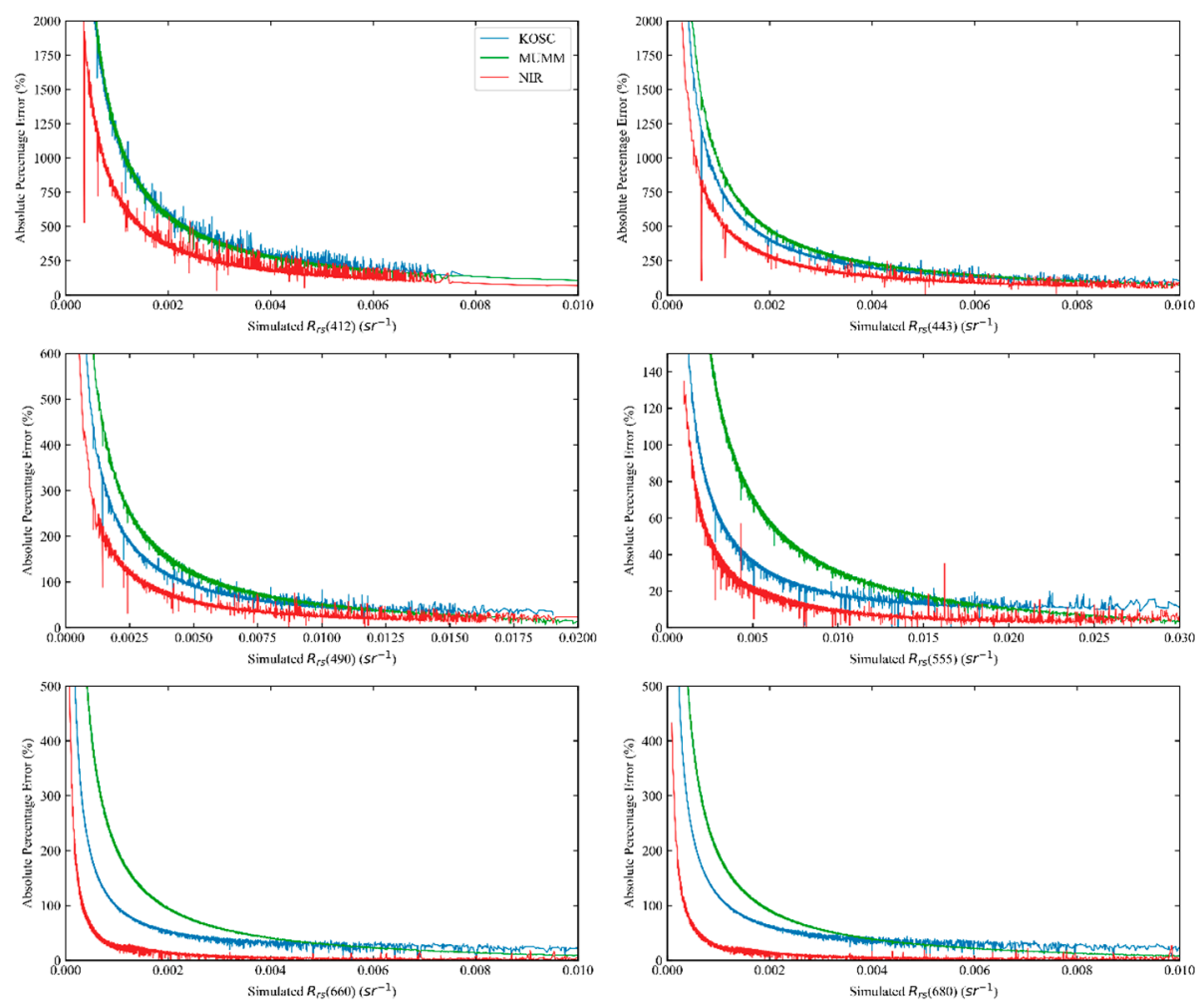

Figure 6. Mean absolute percentage deviation (APD) of remote sensing reflectance (Rrs) retrieved from KOSC, MUMM, and NASA-STD algorithms as a function of simulated Rrs at 412, 443, 490, 555, 660 , and $680 \mathrm{~nm}$.

\subsection{AC Algorithm Applicable Area Division}

The division result is shown in Figure 7. The application area of the UV algorithm is mainly distributed in the offshore areas of Hangzhou Bay, the Yangtze River Estuary, and Subei Shoal. The application area of the NIR algorithm is mainly located offshore. In the clean water body far from the shore, most of the pixels on the image belong to the applicable area of the NIR algorithm.

The UV AC (412 nm) algorithm and NASA-STD NIR AC algorithm are respectively applied to the areas shown in Figure 7, and the inverted remote sensing reflectance Rrs is shown in Figure 8. The UV algorithm shows good Rrs distribution in the $412-680 \mathrm{~nm}$ band. We use the NASA-STD NIR algorithm in the area where the NIR AC algorithm is applied. Good remote sensing reflectance results can be obtained in clear water bodies far offshore, but NASA-STD fails in the nearshore area (white area in Figure 8). Because the water there is still turbid, SeaDAS sets the flag of the pixels as turbid. Pixels cannot be processed using the NASA-STD NIR algorithm. We use the UV AC (412 nm) algorithm for processing these pixels. 


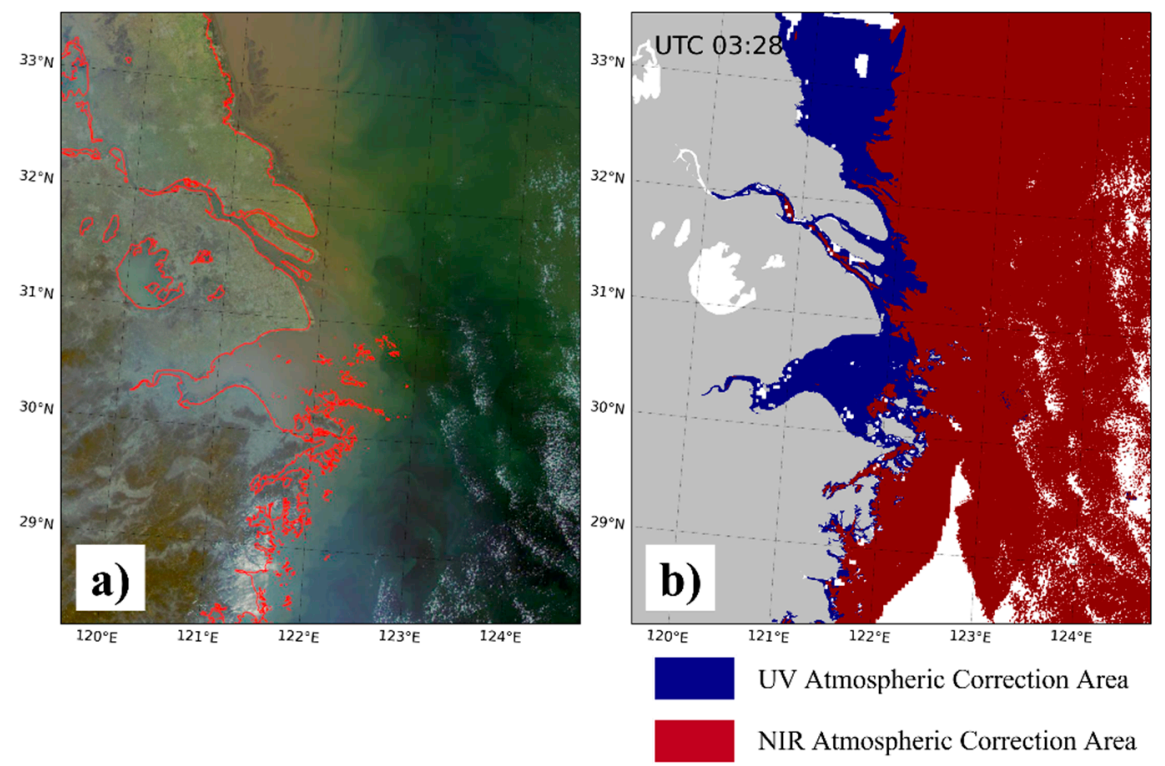

Figure 7. Areas where the UV and NIR AC algorithms are applicable. The blank area on the image indicates cloud cover. (a) The true-color image of the GOCI sensor in the Yangtze River Estuary area at 11:30 on 1 March 2016. (b) Shows the application areas of the UV and NIR AC algorithms.
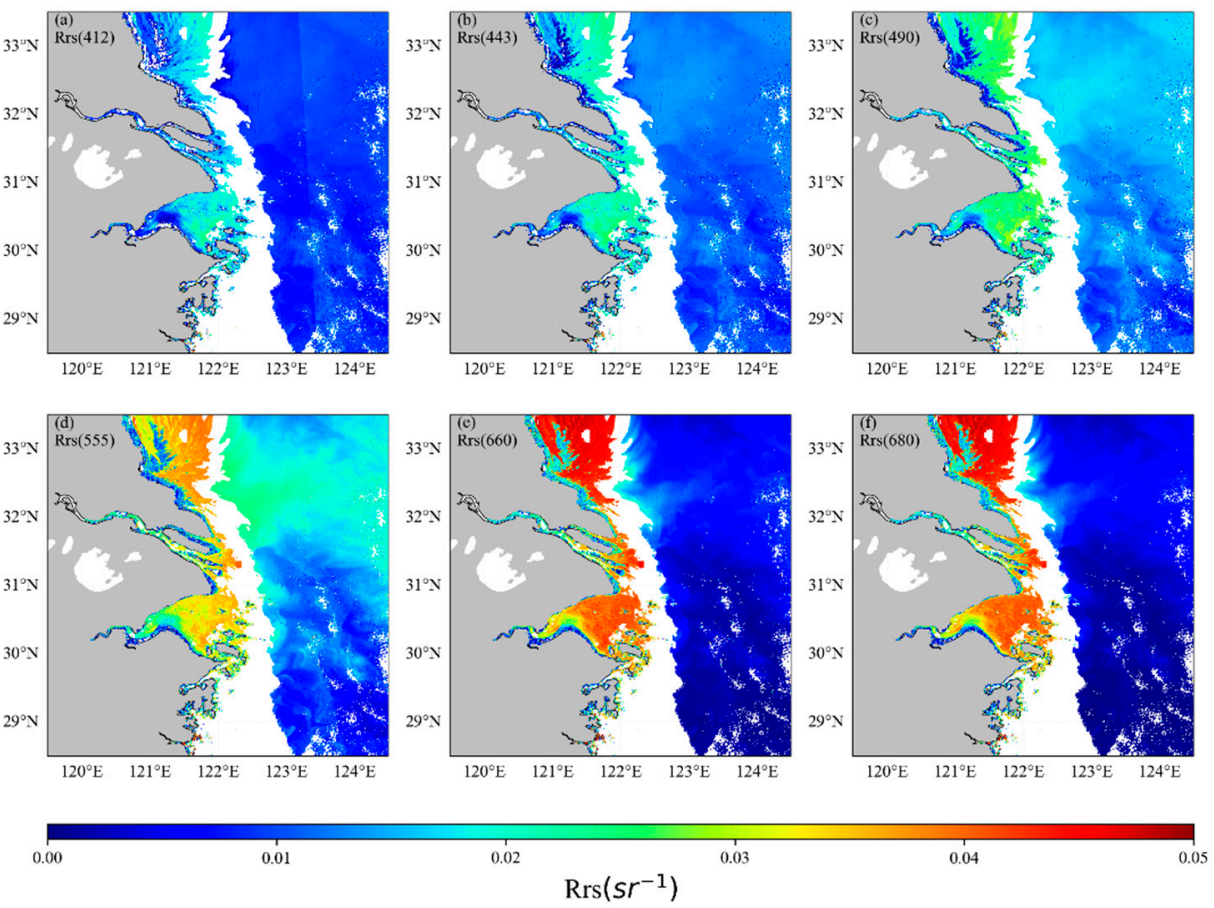

Figure 8. Atmospheric correction Rrs distributions (unit: $\mathrm{sr}^{-1}$ ) at (a-f) 412, 443, 490, 555, 660, $680 \mathrm{~nm}$ on the Changjiang Estuary on 1 March 2016 by applying NASA-STD and UV algorithms to the applicable areas of NIR and UV. The black is the area where the NASA-STD algorithm fails, and the white is the cloud.

The UV algorithm can be used for effective inversion where the application area of the NIR algorithm cannot be retrieved, which increases the coverage area of the remote sensing reflectance products. However, this method has a clear dividing line in the area where the remote sensing reflectance of the UV and NIR algorithms intersect (Figure 9). The remote sensing reflectance jumps a lot there, which does not conform to the actual ocean water condition and is not continuous in space. It is necessary to smooth the transition from the UV algorithm to the NIR algorithm. 


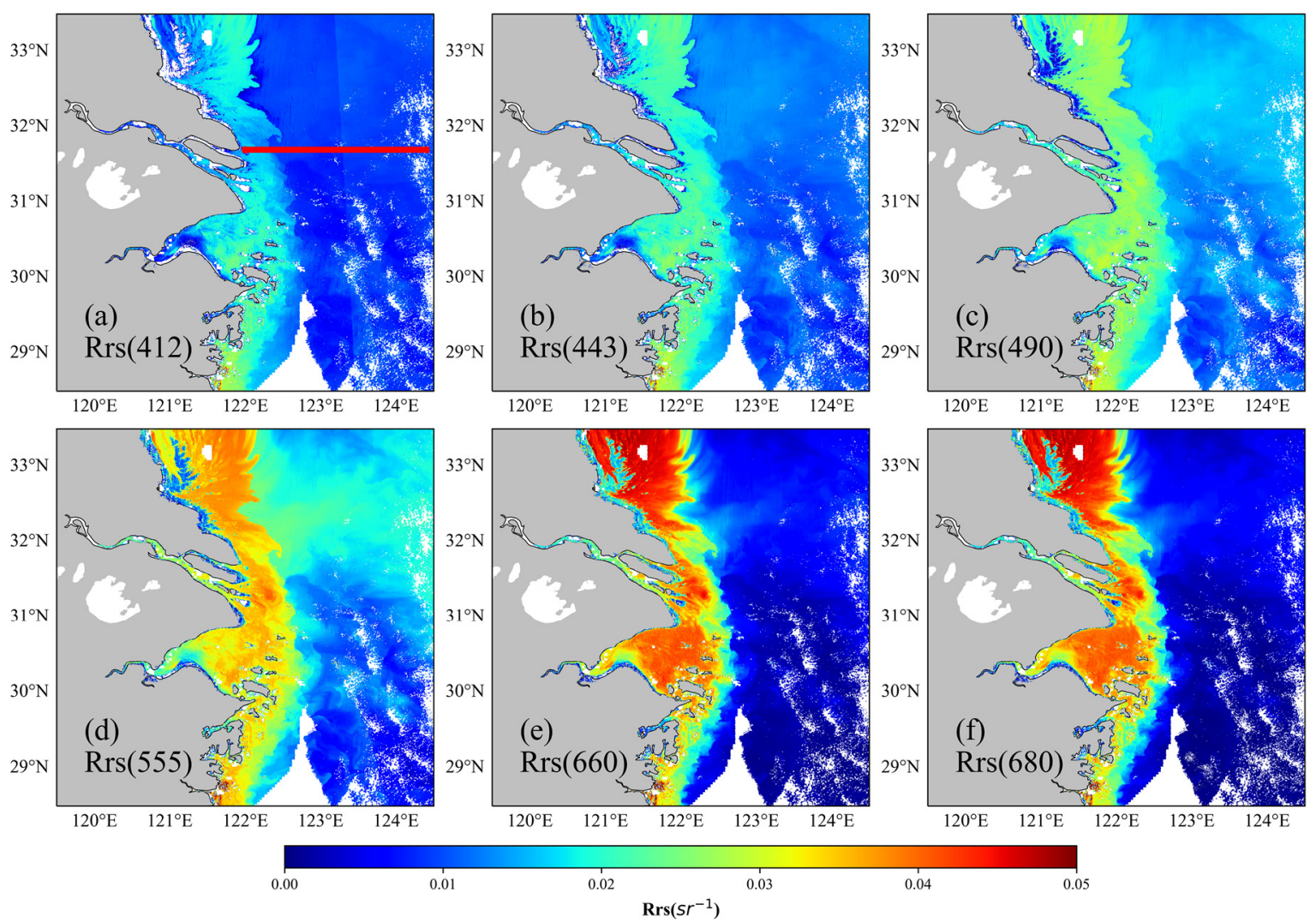

Figure 9. UV-NIR atmospheric correction Rrs distributions (unit: $\mathrm{sr}^{-1}$ ) at (a-f) 412, 443, 490, 555, 660, 680 nm on the Changjiang Estuary on 1 March 2016 by applying the UV algorithm to the NASA-STD algorithm failure area. The red line in panel (a) refers to the location and direction of the transect used in Figure 10.
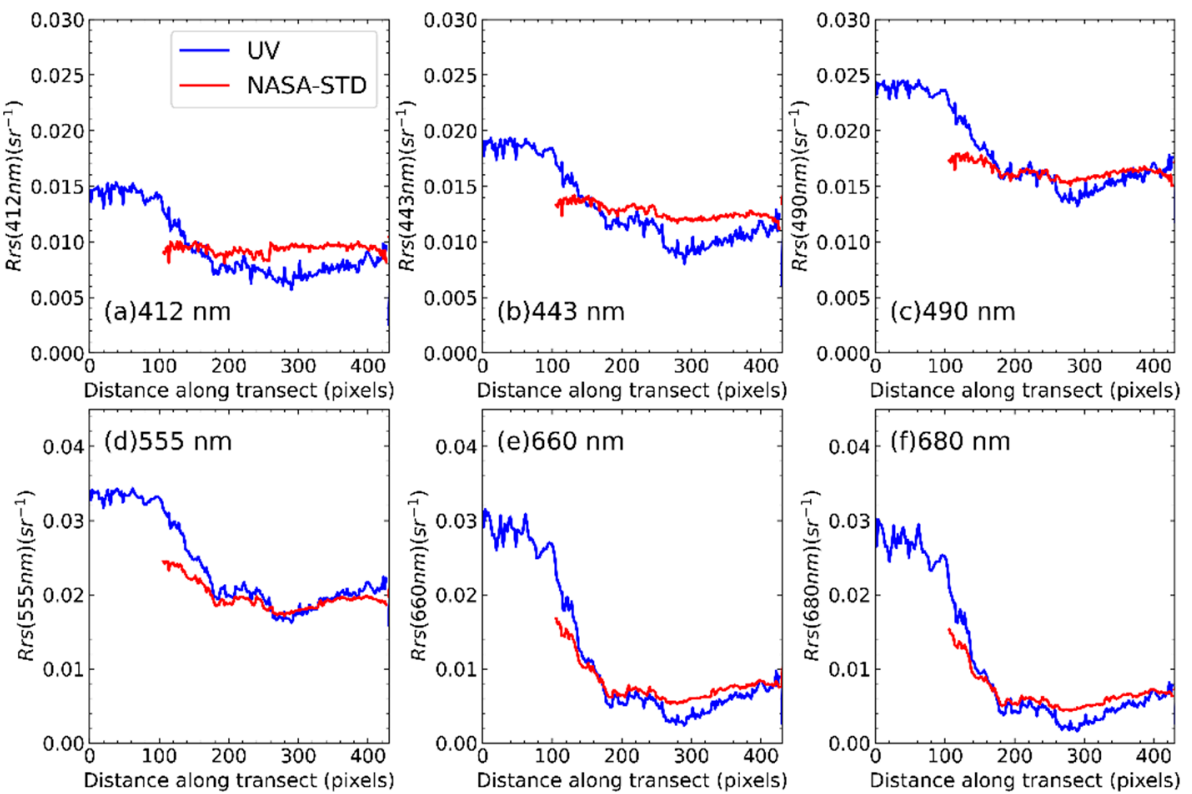

Figure 10. Comparison of Rrs extracted from the pixel along the red arrow in Figure 9a at wavelengths of (a) 412, (b) 443, (c) 490, (d) 555, (e) 660, and (f) $680 \mathrm{~nm}$. Zero on the $x$-axis indicates the location is the closest to the coast.

\subsection{Comparison of AC Results}

We also extracted the Rrs values for pixels along the red line in Figure 9. It covers the high-turbidity water body of the estuary and the offshore low-turbidity water body; 
their profiles are shown in Figure 10. A distance of 0 along the $x$-axis indicates the location is the closest to the coast. In general, $R_{r s}$ values are low in the open ocean and high near the coast. At $\sim 0-100$ pixels along the transect, the NASA-STD algorithm is invalid. At the beginning of NASA-STD AC, the difference of results between the UV and NASASTD algorithms is relatively large. Splicing here will cause a jump, so it is necessary to perform an algorithm conversion where the two are equal. At about 150 pixels, there is an intersection between the UV algorithm and NASA-STD NIR remote sensing reflectance curve, indicating that the remote sensing reflectance of the two is equal; after 150 pixels, the remote sensing reflectance of the UV AC (412 nm) algorithm continues to decrease; the NASA-STD NIR algorithm remote sensing changes smoothly in the $412-490 \mathrm{~nm}$ band, and gradually decreases in the 555-680 $\mathrm{nm}$ band, but the NIR algorithm remote sensing reflectance curve is always above the UV algorithm curve. The algorithm is switched there, the remote sensing reflectance (Rrs) transitions smoothly in space, and there will be no obvious dividing line.

\subsection{Algorithm Performance Evaluation Using Satellite Image}

The results of the new algorithm are compared with those processed by NASA-STD, MUMM, KOSC-STD, and UV algorithms. Figures 11 and 12 show that the NASA-STD AC algorithm does not have effective inversion values in the Changjiang Estuary and the Bohai Sea. The data loss is more serious in Hangzhou Bay and the Subei Shoal. The inversion effect is better in clean-water bodies far offshore. The UV AC (412 nm) algorithm can make up for the shortcoming of the NASA-STD algorithm, namely, not have an effective inversion value for turbid waters near the coast, but UV AC (412 nm) remote sensing reflectance appears a lot of negative values in the clean waters of the eastern Bohai Sea, which is displayed on the image after the negative value mask, and there are negative pixels in the 680-nm band in the East China Sea. In clean waters, there are no high concentrations of chlorophyll and yellow substances, and the light absorption of the water is weak. If the 412-nm band is regarded as a "dark pixel," the Rayleigh-corrected reflectance of this band is regarded as aerosol reflectance. Aerosol scattering ratio extrapolation will overestimate the contribution of aerosol scattering on clean water, and the aerosols "flat" assumption is no longer applicable, so there will be a situation where the remote sensing reflectance of the clean-water body is negative, indicating that the UV AC (412 nm) algorithm does not apply to the clean-water body. The UV-NIR AC algorithm can effectively perform inversion in both near-shore turbid waters or clean ocean waters, indicating that the combined algorithm has the advantages of both NASA-STD NIR and UV algorithms and can effectively improve the coverage area of remote sensing reflectance.

\subsection{Evaluation of UV-NIR AC Using In-Situ Data}

The slope in the overall Rrs match-ups for NASA-STD, UV, and UV-NIR algorithms are $0.801,0.689$, and 0.976 , with an intercept of $0.00028,0.00032$, and 0.00009 , respectively (Figure 13). Table 4 shows that the combined algorithm has the best performance, the RMSE is between 0.0017 and $0.0025, R^{2}$ is between 0.77 and 0.94 , and the relative error is between $12.95 \%$ and $23.37 \%$. Among them, the relative error in the $443-660 \mathrm{~nm}$ band is less than 20\%; and the average relative error appears in the $490-\mathrm{nm}$ band, which is $12.95 \%$; and the largest appears in the $412-\mathrm{nm}$ band, which is $23.37 \%$. The NASA-STD NIR algorithm significantly underestimates the remote sensing reflectance. Bias is between -0.0029 and -0.0011 , and there is a small amount of negative values in the 412-nm band. The RMSE is between 0.0020 and 0.0036 . The relative error is between $18.35 \%$ and $26.75 \%$, and the average relative error is in the $412-555 \mathrm{~nm}$ band. The UV AC (412 nm) algorithm is slightly better than the NASA-STD AC algorithm; The $660 \mathrm{~nm}$ band error is the largest, with APD of $25.93 \%$ and a lot of negative values. 

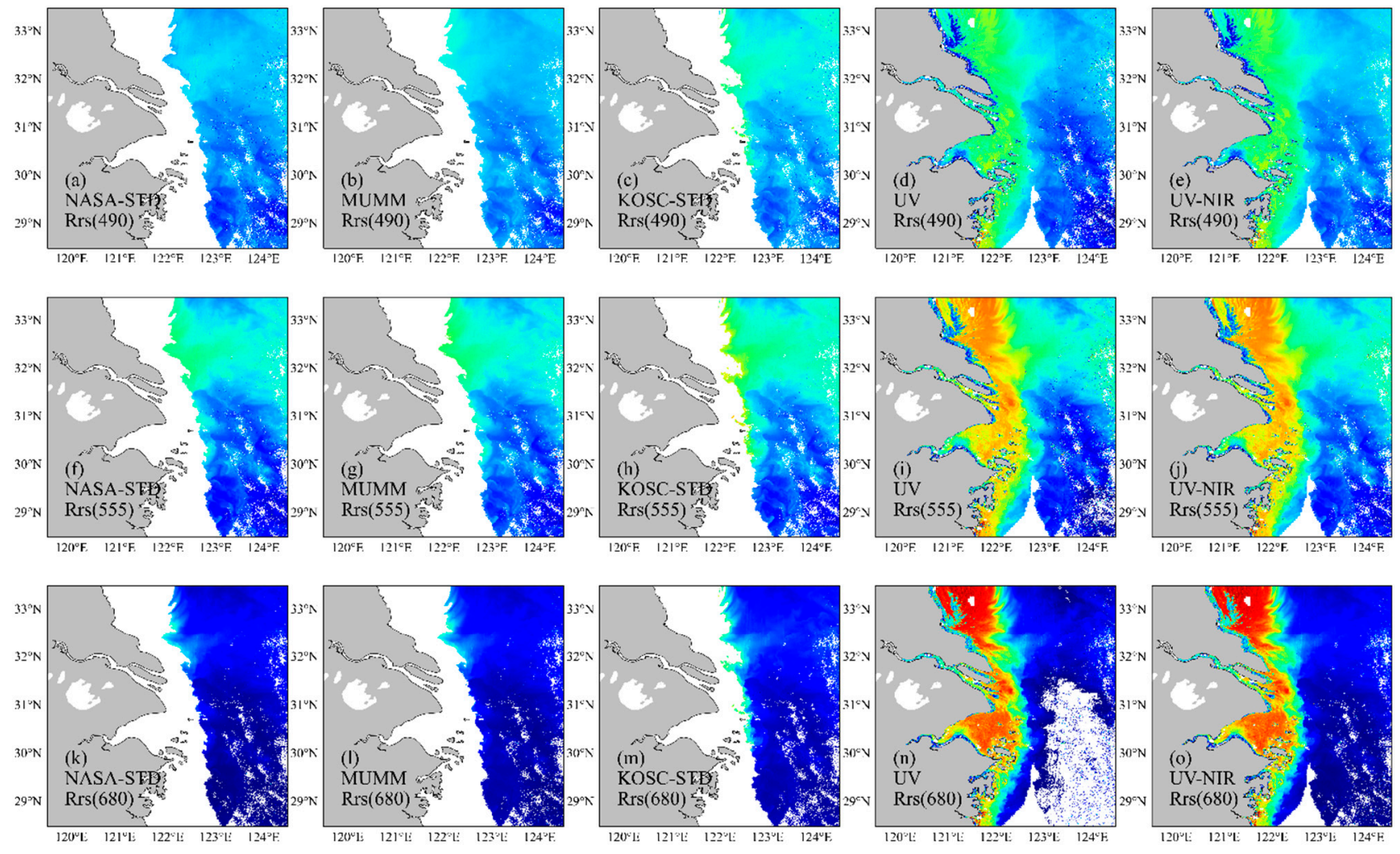

$\operatorname{Rrs}\left(s r^{-1}\right)$

Figure 11. Comparison of Rrs distributions (units: $s r^{-1}$ ) at (a-e) $490,(\mathbf{f}-\mathbf{j}) 555$, and (k-o) $680 \mathrm{~nm}$ on the Changjiang Estuary on 1 March 2016, and processed by NASA-STD, MUMM, KOSC-STD, UV, and UV-NIR algorithms, respectively.
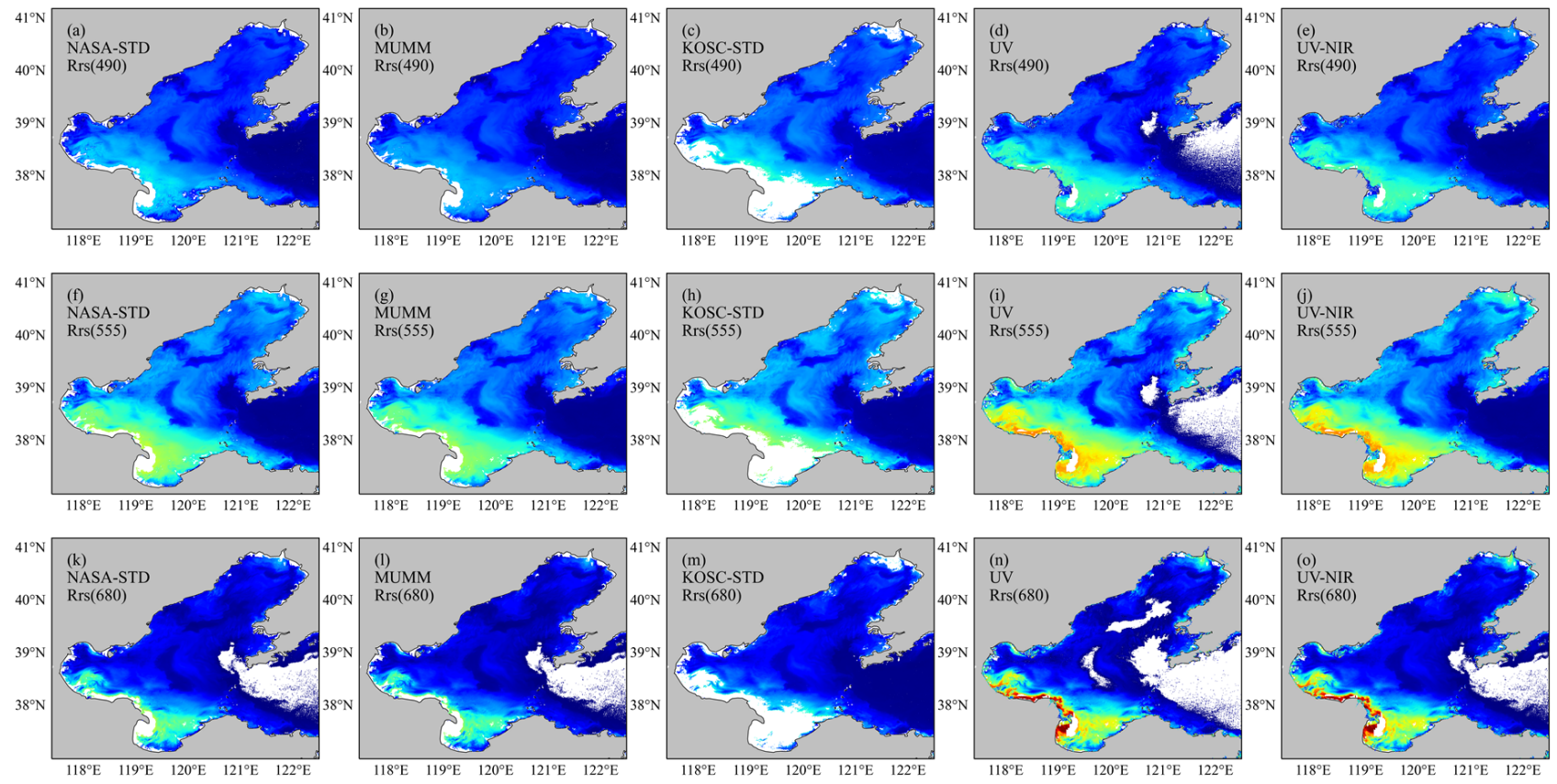

$\operatorname{Rrs}\left(S r^{-1}\right)$

Figure 12. Comparison of Rrs distributions (unit: $s r^{-1}$ ) at (a-e) 490, (f-j) 555, and (k-o) $680 \mathrm{~nm}$ in the Bohai Sea on 26 August 2016, and processed by NASA-STD, MUMM, KOSC-STD, UV, and UV-NIR algorithms, respectively. 

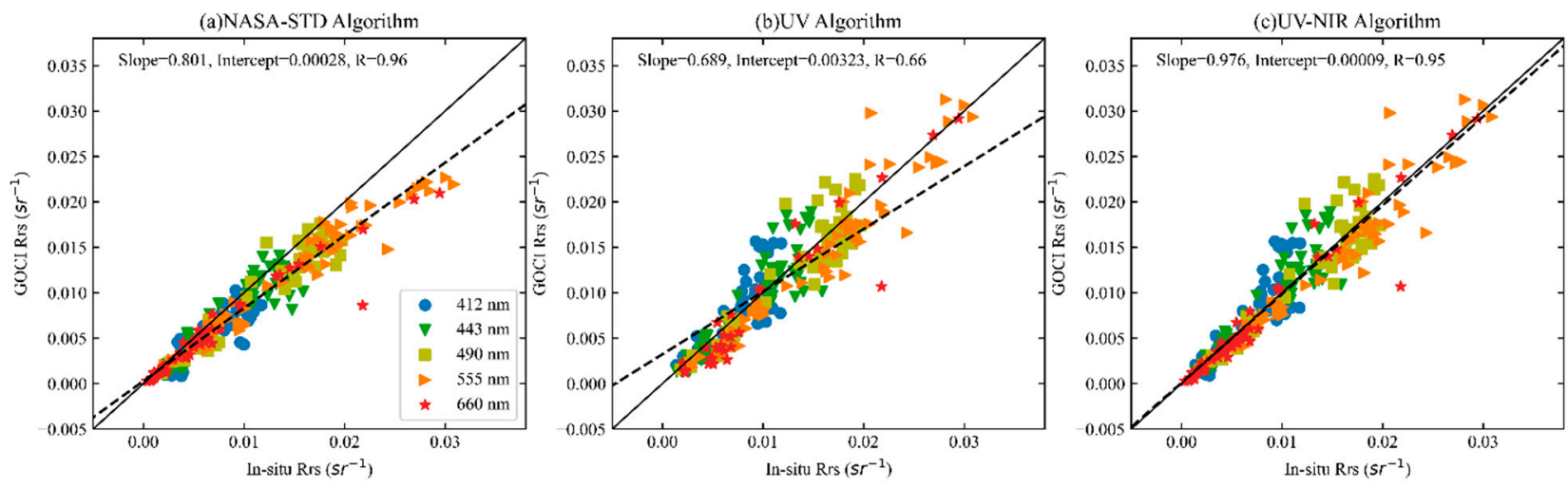

Figure 13. Scatter plots of remote sensing reflectance inversion values and measured values using (a) NASA-STD algorithm, (b) UV algorithm, and (c) UV-NIR algorithms.

Table 4. Statistical results of remote sensing reflectance inversion and measured values of three AC algorithms.

\begin{tabular}{ccccccccc}
\hline $\begin{array}{c}\text { AC } \\
\text { Algorithm }\end{array}$ & $\boldsymbol{R}_{r s}(\lambda)$ & APD & $\begin{array}{c}\text { RMSE } \\
\left(s r^{-1}\right)\end{array}$ & $\begin{array}{c}\text { Bias } \\
\left(s r^{-1}\right)\end{array}$ & $\boldsymbol{R}^{2}$ & Slope & Intercept & N \\
\hline \multirow{3}{*}{ NASA- } & 412 & 26.75 & 0.0020 & -0.0014 & 0.77 & 0.84 & -0.0002 & 49 \\
STD & 443 & 19.01 & 0.0020 & -0.0011 & 0.85 & 0.85 & 0.0002 & 57 \\
& 590 & 18.35 & 0.0025 & -0.0019 & 0.91 & 0.86 & -0.0002 & 59 \\
& 660 & 18.78 & 0.0036 & -0.0029 & 0.94 & 0.78 & 0.0004 & 59 \\
& 412 & 21.68 & 0.0025 & -0.0012 & 0.93 & 0.72 & 0.0004 & 58 \\
\hline \multirow{2}{*}{ UV } & 443 & 17.64 & 0.0023 & 0.0006 & 0.71 & 1.10 & -0.00006 & 53 \\
& 490 & 15.41 & 0.0023 & -0.0004 & 0.86 & 1.04 & -0.0010 & 58 \\
& 555 & 17.94 & 0.0028 & -0.0015 & 0.91 & 1.03 & -0.0021 & 55 \\
& 660 & 25.93 & 0.0026 & -0.0009 & 0.89 & 1.01 & -0.0001 & 32 \\
\hline \multirow{4}{*}{ UV-NIR } & 412 & 23.37 & 0.0022 & 0.0006 & 0.76 & 1.13 & -0.0003 & 59 \\
& 443 & 16.89 & 0.0021 & 0.0004 & 0.84 & 1.06 & -0.0001 & 59 \\
& 490 & 12.95 & 0.0021 & -0.0002 & 0.87 & 1.03 & -0.0021 & 59 \\
& 555 & 13.86 & 0.0025 & -0.0012 & 0.92 & 0.99 & -0.0011 & 59 \\
& 660 & 19.53 & 0.0017 & -0.0003 & 0.93 & 0.97 & -0.0002 & 59 \\
\hline
\end{tabular}

\section{Conclusions}

In this paper, the East China Sea is used as a research area, and the GOCI sensor data are selected to study AC methods. Aimed at current problems in the AC of coastal waters of the second type, a combined UV and NIR AC method is constructed to realize the AC of remote sensing images of turbid coastal waters.

According to the reflectance after Rayleigh scattering correction in the 412- and 865-nm bands, the image is divided into the applicable area of the UV algorithm and the applicable area of the NIR algorithm. Then, the UV and NIR AC algorithms are applied to their respective application areas. The results show that the applicable areas of the UV algorithm are mainly distributed in the offshore areas of Hangzhou Bay, the Yangtze River Estuary, and the Subei Shoal. The water body there is extremely turbid, and the concentration of suspended sediment is high. The applicable areas of the NIR algorithm are mainly distributed in clean-water bodies relatively far from the shore. The applicable area of AC is closely related to the temporal change of tide level. Applying the UV and NASA-STD NIR $\mathrm{AC}$ algorithms directly to the above areas will cause data discontinuities, and there will be obvious boundary lines on the image.

Based on the analysis of the applicable area of AC. A combined UV and NIR AC algorithm is proposed. Comparing the AC algorithm proposed in this paper with the UV and NASA-STD NIR algorithms, we find that the NASA-STD NIR algorithm has the worst accuracy (APD of 18.35-26.75\%), and there is no effective inversion value in the coastal 
turbid water area. The accuracy of the UV AC (412 nm) algorithm is moderate (APD of 15.41-25.93\%), and there are a small number of negative values in clean-water areas. The combined algorithm has the highest accuracy (APD of 13.86-23.37\%), compared with the two individual algorithms: the average relative errors of 443-660 nm are decreased by $0.75-2.12 \%, 2.46-5.4 \%, 4.08-4.92 \%$, and $2.35-6.4 \%$, and the spatial coverage of data has also been greatly improved.

Author Contributions: Conceptualization, J.C. and F.Q.; methodology, F.Q.; software, F.Q. and Q.Z.; data analysis, F.Q. and Y.X.; investigation, J.C and F.Q.; resources, Q.S., Z.M. and B.H.; writing F.Q. and J.C.; supervision, J.C.; project administration, J.C.; funding acquisition, J.C. All authors have read and agreed to the published version of the manuscript.

Funding: This research was funded by the National Key Research and Development Program of China (Grant No. 2016YFC1400903), NSFC-Zhejiang Joint Fund for the Integration of Industrialization and Informatization (Grant No. U1609202), Key Special Project for Introduced Talents Team of Southern Marine Science and Engineering Guangdong Laboratory (Guangzhou) (GML2019ZD0602), and National Natural Science Foundation of China (Grant Nos. 41376184 and 40976109).

Data Availability Statement: The authors thank the Korean Ocean Satellite Center (download URL: http:/ / kosc.kiost.ac.kr/ accessed date 4 October 2021) for providing the GOCI data.

Conflicts of Interest: The authors declare no conflict of interest.

\section{References}

1. Choi, J.-K.; Park, Y.J.; Ahn, J.H.; Lim, H.-S.; Eom, J.; Ryu, J.-H. GOCI, the World's First Geostationary Ocean Color Observation Satellite, for the Monitoring of Temporal Variability in Coastal Water Turbidity. J. Geophys. Res. Ocean. 2012, 117, C09004. [CrossRef]

2. He, X.; Bai, Y.; Pan, D.; Huang, N.; Dong, X.; Chen, J.; Chen, C.-T.A.; Cui, Q. Using Geostationary Satellite Ocean Color Data to Map the Diurnal Dynamics of Suspended Particulate Matter in Coastal Waters. Remote Sens. Environ. 2013, 133, 225-239. [CrossRef]

3. Doxaran, D.; Lamquin, N.; Park, Y.-J.; Mazeran, C.; Ryu, J.-H.; Wang, M.; Poteau, A. Retrieval of the Seawater Reflectance for Suspended Solids Monitoring in the East China Sea Using MODIS, MERIS and GOCI Satellite Data. Remote Sens. Environ. 2014, 146, 36-48. [CrossRef]

4. Chau, P.M.; Wang, C.-K.; Huang, A.-T. The Spatial-Temporal Distribution of GOCI-Derived Suspended Sediment in Taiwan Coastal Water Induced by Typhoon Soudelor. Remote Sens. 2021, 13, 194. [CrossRef]

5. Du, Y.; Lin, H.; He, S.; Wang, D.; Wang, Y.P.; Zhang, J. Tide-Induced Variability and Mechanisms of Surface Suspended Sediment in the Zhoushan Archipelago along the Southeastern Coast of China Based on GOCI Data. Remote Sens. 2021, 13, 929. [CrossRef]

6. Lou, X.; Hu, C. Diurnal Changes of a Harmful Algal Bloom in the East China Sea: Observations from GOCI. Remote Sens. Environ. 2014, 140, 562-572. [CrossRef]

7. Lee, M.-S.; Park, K.-A.; Micheli, F. Derivation of Red Tide Index and Density Using Geostationary Ocean Color Imager (GOCI) Data. Remote Sens. 2021, 13, 298. [CrossRef]

8. Hu, Z.; Wang, D.P.; Pan, D.; He, X.; Miyazawa, Y.; Bai, Y.; Wang, D.; Gong, F. Mapping Surface Tidal Currents and Changjiang Plume in the East China Sea from Geostationary Ocean Color Imager. J. Geophys. Res. Ocean. 2016, 121, 1563-1572. [CrossRef]

9. Park, K.-A.; Lee, M.-S.; Park, J.-E.; Ullman, D.; Cornillon, P.C.; Park, Y.-J. Surface Currents from Hourly Variations of Suspended Particulate Matter from Geostationary Ocean Color Imager Data. Int. J. Remote Sens. 2018, 39, 1929-1949. [CrossRef]

10. Chen, J.; Chen, J.; Cao, Z.; Shen, Y. Improving Surface Current Estimation From Geostationary Ocean Color Imager Using Tidal Ellipse and Angular Limitation. J. Geophys. Res. Ocean. 2019, 124, 4322-4333. [CrossRef]

11. Wang, M.; Shi, W.; Jiang, L. Atmospheric Correction Using Near-Infrared Bands for Satellite Ocean Color Data Processing in the Turbid Western Pacific Region. Opt. Express 2012, 20, 741. [CrossRef]

12. Gordon, H.R.; Wang, M. Retrieval of Water-Leaving Radiance and Aerosol Optical Thickness over the Oceans with SeaWiFS: A Preliminary Algorithm. Appl. Opt. 1994, 33, 443. [CrossRef] [PubMed]

13. Gordon, H.R.; Wang, M. Surface-Roughness Considerations for Atmospheric Correction of Ocean Color Sensors 1: The RayleighScattering Component. Appl. Opt. 1992, 31, 4247. [CrossRef] [PubMed]

14. Wang, M. The Rayleigh Lookup Tables for the SeaWiFS Data Processing: Accounting for the Effects of Ocean Surface Roughness. Int. J. Remote Sens. 2002, 23, 2693-2702. [CrossRef]

15. Shanmugam, V.; Shanmugam, P.; He, X. New Algorithm for Computation of the Rayleigh-Scattering Radiance for Remote Sensing of Water Color from Space. Opt. Express 2019, 27, 30116. [CrossRef]

16. Liu, G.; Li, Y.; Lyu, H.; Wang, S.; Du, C.; Huang, C. An Improved Land Target-Based Atmospheric Correction Method for Lake Taihu. IEEE J. Sel. Top. Appl. Earth Obs. Remote Sens. 2016, 9, 793-803. [CrossRef] 
17. Wang, M.; Jiang, L. Atmospheric Correction Using the Information From the Short Blue Band. IEEE Trans. Geosci. Remote Sens. 2018, 56, 6224-6237. [CrossRef]

18. Pan, Y.; Shen, F.; Verhoef, W. An Improved Spectral Optimization Algorithm for Atmospheric Correction over Turbid Coastal Waters: A Case Study from the Changiiang (Yangtze) Estuary and the Adjacent Coast. Remote Sens. Environ. 2017, 191, 197-214. [CrossRef]

19. Gordon, H.R. Removal of Atmospheric Effects from Satellite Imagery of the Oceans. Appl. Opt. 1978, 17, 1631. [CrossRef]

20. Shettle, E.; Fenn, R. Models for the Aerosols of the Lower Atmosphere and the Effects of Humidity Variations on Their Optical Properties. Environ. Res. 1979, 94, 504.

21. Ahmad, Z.; Franz, B.A.; McClain, C.R.; Kwiatkowska, E.J.; Werdell, J.; Shettle, E.P.; Holben, B.N. New Aerosol Models for the Retrieval of Aerosol Optical Thickness and Normalized Water-Leaving Radiances from the SeaWiFS and MODIS Sensors over Coastal Regions and Open Oceans. Appl. Opt. 2010, 49, 5545. [CrossRef]

22. Mobley, C.D.; Werdell, J.; Franz, B.; Ahmad, Z.; Bailey, S. Atmospheric Correction for Satellite Ocean Color Radiometry. Tech. Rep. 2016, 85. [CrossRef]

23. Bailey, S.W.; Franz, B.A.; Werdell, P.J. Estimation of Near-Infrared Water-Leaving Reflectance for Satellite Ocean Color Data Processing. Opt. Express 2010, 18, 7521. [CrossRef] [PubMed]

24. Ahn, J.-H.; Park, Y.-J. Estimating Water Reflectance at Near-Infrared Wavelengths for Turbid Water Atmospheric Correction: A Preliminary Study for GOCI-II. Remote Sens. 2020, 12, 3791. [CrossRef]

25. Xue, C.; Chen, S.; Lee, Z.; Hu, L.; Shi, X.; Lin, M.; Liu, J.; Ma, C.; Song, Q.; Zhang, T. Iterative Near-Infrared Atmospheric Correction Scheme for Global Coastal Waters. ISPRS J. Photogramm. Remote Sens. 2021, 179, 92-107. [CrossRef]

26. Pahlevan, N.; Roger, J.-C.; Ahmad, Z. Revisiting Short-Wave-Infrared (SWIR) Bands for Atmospheric Correction in Coastal Waters. Opt. Express 2017, 25, 6015. [CrossRef] [PubMed]

27. Goyens, C.; Jamet, C.; Schroeder, T. Evaluation of Four Atmospheric Correction Algorithms for MODIS-Aqua Images over Contrasted Coastal Waters. Remote Sens. Environ. 2013, 131, 63-75. [CrossRef]

28. Wang, M.; Wei, S. The NIR-SWIR Combined Atmospheric Correction Approach for MODIS Ocean Color Data Processing. Opt. Express 2007, 15, 15722-15733. [CrossRef]

29. Shi, W.; Wang, M. An Assessment of the Black Ocean Pixel Assumption for MODIS SWIR Bands. Remote Sens. Environ. 2009, 11, 1587-1597. [CrossRef]

30. He, X.; Bai, Y.; Pan, D.; Tang, J.; Wang, D. Atmospheric Correction of Satellite Ocean Color Imagery Using the Ultraviolet Wavelength for Highly Turbid Waters. Opt. Express 2012, 20, 20754. [CrossRef]

31. Ahn, J.-H.; Park, Y.-J.; Ryu, J.-H.; Lee, B.; Oh, I.S. Development of Atmospheric Correction Algorithm for Geostationary Ocean Color Imager (GOCI). Ocean Sci. J. 2012, 47, 247-259. [CrossRef]

32. Ruddick, K.G.; Ovidio, F.; Rijkeboer, M. Atmospheric Correction of SeaWiFS Imagery for Turbid Coastal and Inland Waters. Appl. Opt. 2000, 39, 897-912. [CrossRef]

33. Gordon, H.R.; Brown, J.W.; Evans, R.H. Exact Rayleigh Scattering Calculations for Use with the Nimbus-7 Coastal Zone Color Scanner. Appl. Opt. 1988, 27, 862. [CrossRef]

34. O’Reilly, J.E.; Maritorena, S.; O’Brien, M.C.; Siegel, D.A.; Toole, D.; Menzies, D.; Smith, R.C.; Mueller, J.L.; Mitchell, B.G.; Kahru, M. SeaWiFS Postlaunch Calibration and Validation Analyses. NASA Tech. Memo.-SeaWIFS Postlaunch Tech. Rep. Ser. 2000, 55, 1-64.

35. Lee, Z.; Carder, K.L.; Arnone, R.A. Deriving Inherent Optical Properties from Water Color: A Multiband Quasi-Analytical Algorithm for Optically Deep Waters. Appl. Opt. 2002, 41, 5755. [CrossRef] [PubMed]

36. Kotchenova, S.Y.; Vermote, E.F.; Matarrese, R.; Klemm, F.J., Jr. Validation of a Vector Version of the 6 S Radiative Transfer Code for Atmospheric Correction of Satellite Data Part I: Path Radiance. Appl. Opt. 2006, 45, 6762. [CrossRef]

37. Kotchenova, S.Y.; Vermote, E.F. Validation of a Vector Version of the 6S Radiative Transfer Code for Atmospheric Correction of Satellite Data Part II Homogeneous Lambertian and Anisotropic Surfaces. Appl. Opt. 2007, 46, 4455. [CrossRef]

38. Wilson, R.T. Py6S: A Python Interface to the 6S Radiative Transfer Model. Comput. Geosci. 2013, 51, 166-171. [CrossRef]

39. Nechad, B.; Ruddick, K.; Schroeder, T.; Oubelkheir, K.; Blondeau-Patissier, D.; Cherukuru, N.; Brando, V.; Dekker, A.; Clementson, L.; Banks, A.C.; et al. CoastColour Round Robin Data Sets: A Database to Evaluate the Performance of Algorithms for the Retrieval of Water Quality Parameters in Coastal Waters. Earth Syst. Sci. Data 2015, 7, 319-348. [CrossRef]

40. Zibordi, G.; Mélin, F.; Berthon, J.F.; Holben, B.; Slutsker, I.; Giles, D.; D’Alimonte, D.; Vandemark, D.; Feng, H.; Schuster, G. AERONET-OC: A Network for the Validation of Ocean Color Primary Products. J. Atmos. Ocean. Technol. 2009, 26, $1634-1651$. [CrossRef] 